This is the version of a forthcoming article accepted for publication in International Sociology published by Sage: http://iss.sagepub.com/content/by/year

Accepted version downloaded from SOAS Research Online: http://eprints.soas.ac.uk/22499/ and made available under the CC-BY-NC License

\title{
Trust, power or money: What governs business relationships?
}

\author{
Reinhard Bachmann, SOAS University of London \\ Frens Kroeger, Coventry University
}

\begin{abstract}
This article suggests conceptualising trust as a generalised symbolic medium of communication. It is argued that in business relationships trust appears intertwined with other media, such as power or money. Furthermore, it is shown that typical combinations of trust, power and money are dominant in different business systems (liberal vs. coordinated market economies). The overarching aim of this article is to demonstrate that trust is a fundamental concept of social theory and that the theory of generalised symbolic media of communication provides a useful conceptual perspective to integrate trust into social theory.
\end{abstract}

Key words: trust, power, money, generalised symbolic media of communication, combinations of media, business systems 
This is the version of a forthcoming article accepted for publication in International Sociology published by Sage: http://iss.sagepub.com/content/by/year

Accepted version downloaded from SOAS Research Online: http://eprints.soas.ac.uk/22499/ and made available under the CC-BY-NC License

\section{Introduction}

Practitioners and scholars alike have recently placed enormous emphasis on business organisations' capacity to build and maintain trust in their relationships with suppliers, customers and other stakeholders. Clearly, this is not by accident. Inter-organisational relationships which build on trust tend to incur lower transaction costs as the trusting party has less of a need to monitor the trustee (Zaheer et al., 1998). They are typically characterised by increased flexibility and readiness to adapt to each other's interests and needs (Sako, 1998; Luo, 2002), and by greater openness between business partners (Dyer and Chu, 2003; Sydow, 2006). The latter can facilitate innovation which might otherwise not be possible

(Nooteboom, 2006). Especially where two organisations have complementary knowledge or other resources, these brought together can spark off the development of new products, services and production processes.

With all this in mind it seems somewhat surprising that there are also many voices which are sceptical about the notion that trust can really play a decisive role in contemporary business relations. When (over-)enthusiastic trust researchers are heralding a new age of cooperation and trust (e.g. Heckscher and Adler, 2006), they point to examples of fierce price wars in the consumer electronics industry (Financial Times, 2013) or large food retailers simply using their market power to relentlessly squeeze their suppliers (The Guardian, 2011). According to their observations trust has no place in times of hyper-competition and cutthroat profit maximisation.

On closer inspection these two perspectives are less contradictory than it seems. In interorganisational relationships, trust, power and money constitute coordination mechanisms 
This is the version of a forthcoming article accepted for publication in International Sociology published by Sage: http://iss.sagepub.com/content/by/year

Accepted version downloaded from SOAS Research Online: http://eprints.soas.ac.uk/22499/ and made available under the CC-BY-NC License

which are by no means mutually exclusive (also see Bijlsma-Frankema and Costa [2005] on

trust and control). For many firms trust-based relationships with closely cooperating allies are a central precondition for being able to aggressively compete with other business organisations and to play their power games effectively. But also within one and the same relationship trust is typically only one element besides other governance mechanisms. A firm may have some basic trust in a business partner but also consider other means to safeguard against unexpected events that might threaten a vitally important relationship. Vice versa, a firm may secure the fulfilment of basic commitments by a business partner by way of their power but rely on trust where their ability to control their partner's behaviour reaches its limits. In the following, we will undertake to conceptually unravel the interrelations between all three coordination principles which are relevant in regard to governing business relationships: trust, power and money.

In so doing, our main interest lies with trust, whose role in business relationships is, compared to power and money, still not equally well understood. One of the reasons for this is that, unlike money and power, trust has been neglected for the most part of the history of social thought (with few exceptions; e.g. Simmel, 1950). It is only in the last two decades or so, as organisational networks have received increasing attention in organisational practice and research (Zaheer et.al, 2000), that its fundamental importance has been appreciated more fully. In business studies, sociology and the social sciences as a whole, trust has arrived late, yet very forcefully (also see Sztompka, 1996).

While there may indeed be many reasons for the currently widely shared interest in trust (Grey and Garsten, 2001), these undoubtedly include the recent massive decline of trust in some areas of business and society, such as the banking sector (e.g., Gillespie et al., 2012), which has (painfully) confirmed the relevance of trust in today's socio-economic relationships. Where the organisation of economic exchanges is analysed in our highly 
This is the version of a forthcoming article accepted for publication in International Sociology published by Sage: http://iss.sagepub.com/content/by/year

Accepted version downloaded from SOAS Research Online: http://eprints.soas.ac.uk/22499/ and made available under the CC-BY-NC License

developed business world, trust no longer appears as a marginal concept but as a social category which is just as fundamental and important as power and money.

In order to systematically analyse the interconnections between trust, power and money in inter-organisational relationships, the remainder of this paper will first approach these mechanisms from a Transaction Cost Economics (TCE) inspired angle and view them as fundamental governance principles, typically associated with specific organisational forms (section 2). We will then draw on the theory of 'generalised symbolic media of communication' and discuss the question of whether trust can be understood as such a medium of communication and thus be conceptually framed as a mechanism on a par with power and money (section 3). Subsequently, we will examine which combinations of trust, power and money appear viable, expedient and empirically realistic, and how these combinations are facilitated in business relationships (section 4). Following from these insights, we will investigate whether, and if so, how typical combinations of media are associated with specific types of business systems (section 5). The final section (6) will conclude with a short summary of our argument.

\section{Trust, power and money as governance principles}

Transaction Cost Economics offers some valuable insights into the function of trust in business relationships. Despite the fact that Williamson $(1985 ; 1993)$ himself insisted that trust cannot play a significant role in business relationships and its analysis should be restricted to other social exchanges, there are numerous TCE inspired scholars who believe that there is clearly a place for trust within the TCE framework and effectively conceive of trust, power and money as three coordination mechanisms related to different organisational governance regimes. From a TCE point of view, Bradach and Eccles (1989) argue that inter- 
This is the version of a forthcoming article accepted for publication in International Sociology published by Sage: http://iss.sagepub.com/content/by/year

Accepted version downloaded from SOAS Research Online: http://eprints.soas.ac.uk/22499/ and made available under the CC-BY-NC License

organisational relationships based on 'hierarchy' resemble intra-organisational relations, with

one party depending on the other and drawing on power as the key governance principle.

'Market'-based relationships are inter-organisational relationships where money, more than anything else, coordinates the relevant actors' expectations and interactions. And, finally, 'hybrid' forms of cooperation - i.e., network-based relationships - build on trust as the principal coordination mechanism between business partners (also see Powell, 1990; 1996).

In similar vein, Adler (2001) suggests that there are 3 'ideal-typical' governance mechanisms which are relevant in different forms of intra-/inter-organisational relationships: the market principle which operates on the basis of prices; the principle of hierarchy where authority connects expectations and interactions; and 'community', which requires trust as a central mechanism to control communication between the relevant actors.

Bradach and Eccles (1989) as well as Adler (2001) seem to build on the same notion: Trust, power and money can be viewed as coordination mechanisms which channel the expectations of individual and/or collective economic actors and direct social conduct into certain modes of exchange. They trigger specific patterns of interaction and gear expectations in such a way that actors will find it relatively easy to swiftly connect to each other in their relationships. If it is, for example, money that 'talks' in a market-based relationship then actors will know that they need to follow the behavioural patterns designed for buyers or sellers and express their interests in terms of prices. If power or 'hierarchy' is the dominant mode of interaction the relevant actors will draw on behavioural repertoires internalised in previous situations where they either have followed the demands of a powerful actor or mobilised their own power resources in order to ensure coordinated interaction with their subordinates. In the case of trust, actors take the roles of trustors or trustees, and the trustor will behave as if more information was available than there actually is, and their positive expectations of the trustee's future behaviour was a certainty. Trustors thus accept the risk 
This is the version of a forthcoming article accepted for publication in International Sociology published by Sage: http://iss.sagepub.com/content/by/year

Accepted version downloaded from SOAS Research Online: http://eprints.soas.ac.uk/22499/ and made available under the CC-BY-NC License

that their expectations may be disappointed in exchange for the chance to reap the benefits of a trust-based relationship which, for example, can save costs that would occur with extensive control and monitoring efforts or enable mutually beneficial cooperative relationships leading to innovation and shared economic success.

On the basis of these considerations one can safely conclude that trust has a fundamental function in business relationships and that it is not just a nice accessory to complement a harmonious corporate culture or participatory management style. Consistent with some strands of sociological research, we propose trust to be one of the most important and deepseated mechanisms that can secure successful interaction in business relationships. Its widespread utilisation could - in Kantian terms - even be seen as a 'condition of the possibility' of the existence of differentiated socio-economic systems (Luhmann, 1979; Giddens, 1990).

Putting the significance of trust on a par with power and money seems an important step in understanding the role of trust in today's business world. However, the TCE inspired conceptualisation of trust also has some severe limitations. Possibly the most restrictive among these is its tendency to view the three coordination mechanisms as relatively separate from one another. Despite the fact that Bradach and Eccles (1989) as well as Adler (2001) allow combinations of these mechanisms, they are rather silent on how to systematically account for mixtures of trust, power and money and to elicit, for instance, the effects of trust alongside those of power in hierarchies or money in markets.

Moving away from the institutional economics oriented view and looking more at sociological approaches to conceptualising trust, some groundwork has been done in this strand of literature with regard to the question of whether and how trust and power could be combined within one and the same business relationship (Bachmann, 2001). In these studies, however, money is largely ignored. Sociological trust research has, thus, so far equally failed to take on the task to carefully reconstruct the manifold possibilities of the complex interplay 
This is the version of a forthcoming article accepted for publication in International Sociology published by Sage: http://iss.sagepub.com/content/by/year

Accepted version downloaded from SOAS Research Online: http://eprints.soas.ac.uk/22499/ and made available under the CC-BY-NC License

between different forms of trust, power and money. In the following, we will explore whether

the theory of generalised symbolic media (as a specifically sociological theory) may be able to offer a deeper and more systematic understanding of how money, power and trust can jointly do their jobs within a single business relationship.

\section{Trust, power and money as generalised symbolic media}

\section{Luhmann's media-theoretical approach}

Sociological media theory - interestingly not so different from the TCE approach and Adler's view with regard to what are perceived as main social coordination mechanisms - in our view indeed offers a fruitful perspective for analysing the intricate interplay of trust, power and money. Initially, Parsons (1977 and elsewhere) had developed the theory of generalised symbolic interaction. Luhmann $(1976 ; 1995)$ drew on this approach and presented a revised version of this theoretical perspective which appears more informative with regard to our interest in the combinability of media. He suggests four basic generalised symbolic media of communication in society - money, power, truth/normative judgement and love - and allows for quite a few more media which he calls 'codes' if they are structured in a binary manner. For example, art, religion or the medical discourse can build on such codes and constitute more specific domains in differentiated societies which interfere with the four more general media in complex combinations. Also, Luhmann himself (1979) has presented a thorough investigation of the concept of trust which, at least implicitly, suggests that trust may be seen as a generalised symbolic medium of communication, very similar to power and money. He stops short of stating this explicitly.

Luhmann's media-theoretical considerations open up a promising approach to the question of how exactly trust, power and money might be combined in business relationships. 
This is the version of a forthcoming article accepted for publication in International Sociology published by Sage: http://iss.sagepub.com/content/by/year

Accepted version downloaded from SOAS Research Online: http://eprints.soas.ac.uk/22499/ and made available under the CC-BY-NC License

In order to address this issue we suggest investigating whether power and trust - the latter, of course, remaining the focus of our interest - may be conceptualised as second-order media of communication which could in business relationships draw upon money as the overriding principle. In light of such theoretical views, it may be helpful to examine some of the basic premises underlying Luhmann's systems theoretical approach.

\section{What are generalised symbolic media of communication?}

Luhmann's understanding of generalised symbolic media clearly owes to analogies to language (a re-orientation in late $20^{\text {th }}$ century social theory which he shares with Habermas [1984/1987] and others). For Luhmann, the function of generalised symbolic media of communication begins where the effectiveness of ordinary language ends. As modern societies become ever more differentiated and social functions are more and more specialised, all three elements of communication - i.e., that a message is created, transmitted, and especially that it is understood - become increasingly improbable (Luhmann 1981). Under these conditions, ordinary language is too varied and indeterminate to create sufficient social order on its own. Indeed, it is fit to exacerbate the problem of complexity, as it generates more rather than less communicative options, making it more difficult to link social actions ('speech acts' for that matter) into one another, and this is exactly where generalised symbolic media of communication and their function within complex structures of interaction appear to have their place and purpose.

In principle, every social action is liable to draw boundaries, introduce arbitrary distinctions, and thus create an excess of possibilities. From these possibilities, selections need to be made and stabilised (Krieger, 1996). This is what, in Luhmann's view, makes generalised symbolic media of communication indispensable in differentiated modern 
This is the version of a forthcoming article accepted for publication in International Sociology published by Sage: http://iss.sagepub.com/content/by/year

Accepted version downloaded from SOAS Research Online: http://eprints.soas.ac.uk/22499/ and made available under the CC-BY-NC License

societies (Morgner, 2014). They allow for the transfer of meaning despite the latter's inherent

tendency to be context-bound, the problem that the content of the communication should be able to reach actors not present in the immediate face-to-face situations, as well as the challenge that the recipient of a speech act should be able to agree with the ideas communicated by the sender. The underlying principles are selectivity as well as generalization of meaning on the basis of which, specialised signal systems could emerge which are able to convey specific information simpler and faster than ordinary language. They reduce, for example, the number of accepted meanings to those which can be expressed in terms of prices and thus have a huge advantage with regard to the speed and accuracy of the transmission of meaning; but they also ensure the transferability of meaning by generalization of communication formats. As Murphy points out, here 'order results from a confluence of persons' cognitive categories' (1987: 208; also see Morgner, 2014). Thus, it simplifies the structure and magnifies the effectiveness of communication considerably if in a specific context all speech acts can be interpreted in terms of truth/normative judgement, love, power (claims of superiority and their acceptance), money (prices - demanded and paid) or - as we would argue - trust (pre-commitments and fulfilment of expectations). With regard to trust, let us now look at some of its specific characteristics which may indeed suggest that trust can be seen as a generalised symbolic medium of communication, but also consider some objections one might have against such a perspective before we come to a conclusion on this question.

\section{Trust as a generalised symbolic medium: Connections}

Firstly, Luhmann (1979) leaves no doubt that the key function of trust is the reduction of social complexity - an insight which is confirmed throughout current trust research. This is a central argument supporting the view that trust can be seen as a generalised symbolic medium 
This is the version of a forthcoming article accepted for publication in International Sociology published by Sage: http://iss.sagepub.com/content/by/year

Accepted version downloaded from SOAS Research Online: http://eprints.soas.ac.uk/22499/ and made available under the CC-BY-NC License

of communication. Like other media it does so by reducing the number of possible

interpretations and expectations specifically in regard to the motivations and future intentions underlying the actions of a relevant other (Arnoldi, 2010). Where, e.g., the use of money reduces complexity in that it channels the semantics of social actors' communication along the lines of offering and accepting prices (Parsons, 1967), trust suspends overwhelming complexity as it upholds some specific expectations regarding another actor's future behaviour and ignores all other possibilities.

Secondly, trust demonstrates its usefulness - and this is closely related to our first point in situations of double contingency, where social coordination becomes problematic as the future actions of both self and other are a limine unpredictable (Luhmann, 1995; Luhmann, 1976). In such circumstances, actions which follow meaningfully from those of others are unlikely unless behavioural complexity can be reduced effectively. Particularly since Luhmann's autopoietic shift in his theory, media work primarily as success media. Communicative success builds on social actors' capacity to select realistic interpretations and expectations which can be taken as the basis for subsequent communication. Like other media, trust provides a way of making such meaningful connections more likely. Where other media such as power strive to actively reduce the range of actions available to the subordinate party, trust facilitates the coordination of communication by selecting positive expectations about alter ego's future behaviour as the basis for ego's actions (Bachmann, 2001). Thus, we can conclude that trust clearly exhibits traits which suggest that it qualifies as a generalised symbolic medium of communication. However, there are also grounds to challenge this view. At least two questions need to be considered as potential counter-indications.

Trust as a generalised symbolic medium: Potential disconnections 
This is the version of a forthcoming article accepted for publication in International Sociology published by Sage: http://iss.sagepub.com/content/by/year

Accepted version downloaded from SOAS Research Online: http://eprints.soas.ac.uk/22499/ and made available under the CC-BY-NC License

First, one may argue that the concept of generalised symbolic media of communication implies greater transmittability of information than might be assumed for a phenomenon which can be as personal and idiosyncratic as trust? This, however, depends strongly on our perspective on trust. Psychological research has often regarded trust as a micro-level phenomenon, sometimes simply as the result of individual predispositions (Rotter, 1967). In similar vein, Rousseau et al. (1998) define trust as a phenomenon which rests deeply in individual behaviour. If we assume that trust is tied entirely to individual personalities, a transmission of acts of communication would indeed be difficult to conceive on the basis of trust.

However, trust has also been investigated as an inter-subjective phenomenon (Kroeger, 2013). In this social constructionist understanding (Berger and Luckmann, 1967), specific ways of signalling, building, and using trust are externalised and objectified. As a result, trust can be transmitted between (groups of) actors and across organisational boundaries. But even if we do not want to subscribe to this perspective on trust, which directly addresses its mesolevel transmittablility, there is still a wealth of recent research illuminating the impersonal aspects of trust and its creation - typically on the basis of its institutional embeddedness (Zucker, 1986; Bachmann and Inkpen, 2011). Institutional conditions and antecedents which facilitate and encourage the generation of trust (Lane and Bachmann, 1996; 1997) also provide ways of transmitting trust between actors. This is consistent with the concept of generalised symbolic media, which places emphasis on the chance that actors will select and generalise communicational possibilities which meaningfully connect to other actors' previous acts of communication. Other generalised symbolic media of communication, e.g. power, is not different in this respect, and it would certainly be wrong to assume that trust is so individual or personal in nature that its meaning cannot be transmitted between actors 
This is the version of a forthcoming article accepted for publication in International Sociology published by Sage: http://iss.sagepub.com/content/by/year

Accepted version downloaded from SOAS Research Online: http://eprints.soas.ac.uk/22499/ and made available under the CC-BY-NC License

participating in the same social system, be it a small group or indeed a large socio-economic system.

The second issue one might regard as problematic refers to the fact that trust is not connected to any specific societal subsystem. Where money is the symbolically generalised medium of communication in the economic and power in the political sphere, science and jurisdiction operate through the media of truth and normative judgment, and love has its place in intimate private relationships, trust seems to have a much broader societal application (Luhmann, 1979).

However, the fact that trust is so broadly usable and pervasive, and is not assigned to a specific subsystem, seems not to distance it in categorical terms from the concept of generalised symbolic media of communication. As noted above, Luhmann acknowledges explicitly that not all subsystems have specific media - see for instance education or medicine (Luhmann, 1990; Luhmann and Schorr, 2000) - and that vice versa, not all media are assigned to formalised societal subsystems. Media do not regulate institutionalised subsystems as such, but systems of interaction between individuals which are embedded in the prevalent institutional arrangements that are regulated by media or more specialised binary codes (Morgner, 2014).

\section{Trust as a generalised symbolic medium of communication: Conclusion}

Overall, we can conclude from these considerations that differences between trust and the most 'typical' (and most frequently discussed) generalised symbolic media of communication do not mean that trust is to be discarded as a generalised symbolic medium. Especially, it seems that Luhmann's media concept is flexible enough to allow for a range of qualitatively different media (Dinkel, 2001). Luhmann's conceptualisation thus opens up the concept of generalised symbolic media of communication to historical and empirical 
This is the version of a forthcoming article accepted for publication in International Sociology published by Sage: http://iss.sagepub.com/content/by/year

Accepted version downloaded from SOAS Research Online: http://eprints.soas.ac.uk/22499/ and made available under the CC-BY-NC License

definitions (Chernilo, 2002), resulting in a long and essentially open list of possible media

(see for instance the list provided in Krause, 2005), with four generalised symbolic media of communication being the most fundamental. Consequently, although trust exhibits some differences from power, money and love - most significantly, it is not bound to a specific subsystem but 'societally free-floating' - we would suggest that trust can indeed be seen as a generalised symbolic medium of communication and thus be analysed in the terms of Luhmann's systems theoretical framework.

\section{Trust: A combinable generalised symbolic medium of communication?}

The above insights into the flexibility of Luhmann's theoretical conception seem to fit with the notion of the combinability of media occurring at different levels and prompt us to consider trust as a medium which can govern a relationship in connection with other media such as power or money. In the business world, for example, money may be seen as the overriding medium, supplemented by trust in such a way that the effectiveness of money as a generalised symbolic medium of communication can profit from the existence of trust between a buyer and a seller (Marx, 1962; Parsons, 1967). Thus, we might see money as having a primary function in a specific subsystem of society while trust and/or power may play a secondary role to underpin the functionability of the overriding principle. From our point of view, trust and other media which form the focus of interaction are typically interconnected. Trust can 'piggyback' on the primary media which regulate the more specific aspects of an interaction system. Combined multiple media can create a relation of mutual support so that they enhance (or obstruct) each other's capacity.

\section{Typical combinations of trust, power and money in business relationships}


This is the version of a forthcoming article accepted for publication in International Sociology published by Sage: http://iss.sagepub.com/content/by/year

Accepted version downloaded from SOAS Research Online: http://eprints.soas.ac.uk/22499/ and made available under the CC-BY-NC License

In the following, we will use the above insights to analyse the intricate relationships of trust and power as well as trust and money before we move on to test the combinabilty in the context of two specific business systems. In our view, all of these three media are - to varying degrees - relevant in any business relationship.

\section{Trust and power}

At first glance, it may seem that trust and power are inimical to one another. Either, one might argue, a business relationship is based on power or on trust. Our intuitive understanding of trust largely supports this view. How could power play a role within a firmly trust-based relationship? And why opt for trust if you have the power to arrange things the way you want without the risk of getting betrayed by a trustee? In reality, there are many business contexts where trust and power pull in different directions, but also many situations where trust and power can be combined without much tension occurring between these two mechanisms, i.e. generalised symbolic media of communication.

Consider, for example, a sales manager who has known another firm's purchasing manager face-to-face for a long time and believes that he or she can trust the business partner that when some flexibility is needed in regard delivery times, for instance in the case of unforeseen events, it would be likely that the sales manager is irritated if the purchasing manager showed no understanding and instead insisted solely on the terms of the contract and his or her power to enforce it. It may well be clear to both individuals that there is always some degree of power involved in a business relationship and that the firms they represent have interests which are typically not congruent in a capitalist business environment. Nonetheless, the more both managers have developed a personal relationship, the more they will see the necessity to decide whether trust or power should be the prime coordination mechanism in their relationship in order to avoid awkward and unproductive behaviours. In 
This is the version of a forthcoming article accepted for publication in International Sociology published by Sage: http://iss.sagepub.com/content/by/year

Accepted version downloaded from SOAS Research Online: http://eprints.soas.ac.uk/22499/ and made available under the CC-BY-NC License

that sense, we may say that it is indeed either trust or power which will ultimately dominate a relationship (Bachmann, 2001; also see Tillmar and Lindkvist, 2007).

However, research has also shown that in slightly different circumstances trust and power can go nicely hand in hand (Lane and Bachmann, 1996; 1997), or are even central preconditions of one another (see Möllering [2005], who persuasively makes this argument for trust and control). In particular, this seems to be case where trust and power are not mainly produced and maintained through face-to-face-contacts. In these cases, power typically appears in an abstract and depersonalised form, incorporated in behavioural rules and structural arrangements. Then, power is by no means to be understood as an alternative coordination mechanism to trust. Rather, one can say that resources of power which are not individually available to one side of the relationship but exist, for example, in the form of collectively binding commercial law or social standards of business behaviour, are actually highly conducive to establishing and maintaining trust in a business relationship. Here, many scholars speak of 'system trust' (Luhmann, 1979; Giddens, 1990) or 'institutional-based trust' (Zucker, 1986; Bachmann and Inkpen, 2011) which may govern the relationship between two actors, and it is particularly the latter form of trust that can exist in a symbiotic relationship with power. In other words, power in the form of 'system power' or 'institutional-based power' is highly conducive to (if not a condition of) building trust in business relationships (Bachmann, 2001).

The relevance of the combination of 'system trust' and 'system power' can be exemplified by two business partners who do not know each other at the face-to-face level. In this case, they may still be confident that sufficient depersonalised power, in the form of effective institutional safeguards, exists to make each other's behaviour relatively predictable. They will typically find it easy to build their relationship not only on power but also on trust. In this case, powerful institutions channel their mutual expectations and interaction into certain 
This is the version of a forthcoming article accepted for publication in International Sociology published by Sage: http://iss.sagepub.com/content/by/year

Accepted version downloaded from SOAS Research Online: http://eprints.soas.ac.uk/22499/ and made available under the CC-BY-NC License

directions and thus make their behaviour (mutually) more predictable, i.e., trustworthy (see

Rus and Iglic [2005] for the empirical example of Slovenia). In such circumstances the weaker party has 'good reasons' to trust that his or her business partner will not behave opportunistically and use his or her relatively greater individually available resources of power to ruthlessly maximise his or her individual interests. In other words, power - in the form of institutionalised power - can indeed contribute substantially to building trust-based relationships between business partners (Bachmann, 2001) and both mechanisms, i.e. generalised symbolic media of communication, do not appear as alternative choices at all.

Against the background of these observations, we are inclined to conclude that the answer to the question of how and to what extent trust and power can be combined depends largely on the forms trust and power take on in a specific situation. On the one hand, institutional trust and institutional power can reinforce each other and may thus be seen as combinable generalised symbolic media of communication. On the other, interpersonal trust forms of trust and power - i.e. forms of trust and power which constitutively rest on the dynamics of repeated face-to-face interaction between two individuals - are only combinable to a certain degree and typically require a decision as to where the emphasis should ultimately lie, either on interpersonal trust or on interpersonal power.

Thus, trust and power can be seen as generalised symbolic media of communication which - depending on the context - are more or indeed less combinable. The forms in which trust and power occur determine whether trust can be a secondary generalised symbolic medium of communication riding comfortably on the back of power as primary medium (in the case of institutional forms of trust and power being prevalent), or whether trust appears as a less compatible, sometimes even contradictory, generalised symbolic medium of communication which governs a relationship in which little or no reference is made to the institutional environment (in the case of interpersonal forms of trust and power). In the latter 
This is the version of a forthcoming article accepted for publication in International Sociology published by Sage: http://iss.sagepub.com/content/by/year

Accepted version downloaded from SOAS Research Online: http://eprints.soas.ac.uk/22499/ and made available under the CC-BY-NC License

circumstances, either trust or power can be the primary medium, while the remaining of these two media then functions as the secondary medium.

The following figure depicts the two different types of relationships between trust and power that can occur, with money being the overriding principle in business contexts.

\section{INSERT TABLE 1 ABOUT HERE}

\section{Trust and money}

Let us now focus on the possible relationships between trust and money. As noted above, money usually does not work very effectively without trust. Money is a symbolic token and not a material product, into which, however, it should be convertible at any time (Simmel, 1990; Ingham, 2004). But the latter can be a crucial issue, as historic examples of hyperinflation show all too clearly. Thus, we may say that money often goes hand in hand with trust and sometimes cannot do its job without a significant degree of trust (Beckert, 2006). Similar to some forms of power (i.e. institutional power) and some forms of trust (i.e. institutional trust), money and trust seem to re-confirm each other as generalised media of symbolic interaction, and money is constitutively connected to a considerable degree of trust in many business settings. On closer inspection, however, money can, again similar to power and trust, occur in two qualitatively diverse forms and consequently engage with trust in significantly different ways.

Let us first consider situations where market participants use their private money to make extreme profits at the expense of their business partners. If, for example, a large retailer uses 
This is the version of a forthcoming article accepted for publication in International Sociology published by Sage: http://iss.sagepub.com/content/by/year

Accepted version downloaded from SOAS Research Online: http://eprints.soas.ac.uk/22499/ and made available under the CC-BY-NC License

his or her monetary reserves aggressively to sell below purchasing prices over a long enough

period of time to drive competitors out of the market, this is surely likely to undermine trust which may have existed between this retailer and other players in the market or prevent trust from being developed in the first place. Or, just to take another example, if a firm secretly buys large quantities of shares of a competitor to stage a hostile takeover of this rival, trust will not travel smoothly on the back of money. Against the background of such examples we need to concede that some forms of (using) money are incompatible with a high level of trust. Typically, these are large sums of money which are individually available and instrumentally usable to suspend the conditions of fair competition. Wherever money can be used in this way one has to decide to either draw on money-based incentives or to place greater emphasis on trust, i.e. the belief that the other party will not misuse its monetary resources.

In contrast, the specific forms of money which are particularly compatible with trust appear primarily in situations where the form and distribution of money provide mutual predictability to the exchange partners. Take, for example, the case of an equity-based joint venture. Shared ownership of money can be conducive to building trust in such a relationship, i.e. between two competitors. Here, trust sits comfortably on the back of money and, as a secondary generalised symbolic medium of communication, it adds stability to a business relationship which is primarily organised on the basis of money (as the primary medium). It is usually small money or collectively owned money which - like in the case of power - is not fit for individual misuse, and this makes all the difference. Money which is embodied in infrastructure, education systems, state provided support structures for SMEs etc. falls into this category. In these cases money - i.e., collectively owned or small money - and trust (i.e., institutional-based trust) go nicely hand in hand. If, however, individually available or large money and interpersonal forms of trust are present one usually has to decide whether it is money or trust which should govern the relationship as primary generalised symbolic 
This is the version of a forthcoming article accepted for publication in International Sociology published by Sage: http://iss.sagepub.com/content/by/year

Accepted version downloaded from SOAS Research Online: http://eprints.soas.ac.uk/22499/ and made available under the CC-BY-NC License

medium of communication and which of these mechanisms should have a secondary

function. Of course, to some degree power is also always present in any business relationship and provides an important underpinning principle for such relationship.

The following figure summarises the two different combinations of money and trust that occur in business relationships.

\section{INSERT TABLE 2 ABOUT HERE}

\section{Business systems and typical combinations of generalised symbolic media of communication}

Based on a media theoretical perspective, the historicity and embeddedness of trust, power and money can systematically be incorporated in our analysis. As shown, the system reference of these media is not a one-to-one relationship, in which each generalised symbolic medium of communication is assigned either to a particular organisational form or to a specific societal subsystem. Rather, various combinations of media appear to be viable in different business contexts and gain their specific characteristics through the consistent choice of actions that are compatible within multiple media simultaneously. Following the logic of path-dependency (Schreyögg and Sydow, 2011) such combinations create typical action channels in the respective environments.

Against this background, it seems useful to consider typical combinations of trust, power and money within the context of specific business systems (Whitley, 1992). For the sake of 
This is the version of a forthcoming article accepted for publication in International Sociology published by Sage: http://iss.sagepub.com/content/by/year

Accepted version downloaded from SOAS Research Online: http://eprints.soas.ac.uk/22499/ and made available under the CC-BY-NC License

simplicity and in accordance with the literature on the varieties of capitalism (Hall and

Soskice, 2001), we suggest looking at two ideal-typical business systems in the light of our suggested media theoretical approach: the 'liberal capitalist business system' as represented, for example, by the UK; and the 'coordinated capitalist business system' as present in Germany as well as a number of other countries in mainland Europe.

In a liberal capitalist business environment, we commonly find strong forms of interaction-based power and large individually available resources of money (Bachmann and van Witteloostuijn, 2009). Where powerful actors see a chance to use their power or monetary resources in order to maximise their interests it is quite likely that they will do so. A systematic and comprehensive system of commercial law is largely missing, which leaves room for the more powerful party to dictate the terms of the relationship to the weaker party. Less consistent and less reliable legal and social rules of how to conduct business, combined with a tendency towards short-termism (Lane, 1995), make it normal practice to push individually claimable profits to the limit. In this context, power based on individually available resources and private ownership of large resources of money which can be mobilised very quickly - especially in a stock-exchange based financial system - seem to be just two sides of the same coin.

Trust, by contrast, is a generalised symbolic medium of communication which tends to keep its distance from the other two media in this type of business system. Trust certainly occurs in business as well as other social relationships but it is often not a constitutive element in the coordination of business relationships. Where it is present it primarily takes on the form of interaction-based trust, i.e. it arises from highly personalised relationships in which two individuals build trust on the basis of repeated face-to-face contacts. Despite the fact that trust can be a highly efficient lubricant in business relationships it thus remains a 
This is the version of a forthcoming article accepted for publication in International Sociology published by Sage: http://iss.sagepub.com/content/by/year

Accepted version downloaded from SOAS Research Online: http://eprints.soas.ac.uk/22499/ and made available under the CC-BY-NC License

generalised symbolic medium of communication of local reach and with no strong position

among the fundamental drivers of this system.

By contrast, in the coordinated capitalist business system institutional-based trust typically goes hand in hand with institutional-based power (Lane and Bachmann, 1996). The latter is a form of power that appears as powerful rules which are meant to be, and generally are, accepted as collectively binding. Sometimes this system may be seen as over-regulated and imposing harsh constraints on business activities. However, it is precisely this feature of the system which also feeds strongly into the production of trust, i.e. institutional-based trust (Lane and Bachmann, 1997). Business partners find each other more predictable and aggressive forms of individual profit maximising at the expense of the other party occurs less often in these circumstances. In this business system trust and power engage in a symbiotic relationship where power is particular conducive to fostering trust in business relationships (Bachmann, 2001).

Money is, of course, also not irrelevant in this system. However, it is - as noted above crucial which form and function money takes on. If it is small and slow money, for example when a small or medium-sized firm takes out a loan from a state-controlled regional bank (as is most common practice in this system [Lane, 1995]), then money is a generalised symbolic medium of communication nicely compatible with institutional power and institutional trust. This form of (using) money builds on collectively accepted transparent and powerful rules, and it is thus quite conducive to creating and maintaining trust, i.e. institutional-based trust. If all goes well, power, money and trust all push in the same direction: they suggest long-term business horizons and reduce individual risk as much as opportunities for individual opportunism. Business behaviour in this system tends to be cushioned in many rules and institutional safeguards. The generalised symbolic media of communication that are relevant in governing business relationships in this system are part of a coherent framework which 
This is the version of a forthcoming article accepted for publication in International Sociology published by Sage: http://iss.sagepub.com/content/by/year

Accepted version downloaded from SOAS Research Online: http://eprints.soas.ac.uk/22499/ and made available under the CC-BY-NC License

makes the system as a whole powerful but leaves individual actors with less options to (mis)use their superior position than under a liberal capitalist regime. As this system shows, trust can thrive where capitalism is framed by extensive sets of social rules and legal regulations. This is why the German system, as opposed to the UK for example, has been repeatedly described a high trust system, where individual guile does not necessarily always win the day.

In sum, the liberal capitalist business system primarily draws on money and power (Ganßmann, 1988). Trust is not systematically supported in this system. It does exist, but its reach remains restricted largely to local interaction systems, i.e. interpersonal trust. In the coordinated capitalist system, by contrast, power and trust are the most important generalised symbolic media of communication. Of course, money is (by definition) also in the package here, but much less dominant. Many examples could be found to show that in this system tradition and commitment are often valued over short-term private profits (also see Lane, 1995).

The following table summarises the relevance of each of the 3 generalised symbolic media of communication in each of the two business environments.

\section{INSERT TABLE 3 ABOUT HERE}

These considerations contribute specifically to the debate on cross-national and cross-cultural comparisons of trust (see, e.g., Ertug et al., 2013), by embedding it deeply in the institutional contexts of different countries following different institutional logics. Let us conclude by summarising the implications of our approach more broadly. 
This is the version of a forthcoming article accepted for publication in International Sociology published by Sage: http://iss.sagepub.com/content/by/year

Accepted version downloaded from SOAS Research Online: http://eprints.soas.ac.uk/22499/ and made available under the CC-BY-NC License

\section{Conclusion}

This article's argument goes beyond a TCE inspired view which simply identifies power (hierarchy) money (market) and trust (hybrid arrangements) as the three key governance principles in business contexts. Rather, it suggests a media theoretical conceptualisation of trust, similar to how this sociological approach (particularly in Luhmann's theoretical perspective) has dealt with power and money, to reconstruct the function of trust within complex socio-economic systems. In this perspective, power, money and trust appear as mechanisms which facilitate successful business relationships in that they reduce uncertainty and provide social connectivity among the relevant actors' expectations and interactions. Besides, various combinations of trust, power and money can be analysed within a coherent theoretical framework. Irrespective of the analytical differentiation of these mechanisms which are relevant in business relationships, we have shown that they are often actualised uno actu. They appear as primary and secondary generalised symbolic media of interaction, in combination with a third overriding or underlying medium, and we can also connect typical combinations of media with empirically specifiable business systems. With this approach two important goals can be achieved: first, we provide a contribution to further develop media theoretical ideas and concepts as well as suggesting theoretically guided empirical future research. Second, we suggest a place for trust among the core concepts of sociological theory and contribute to finally putting it where it belongs, namely at the foundations of social theory. As we have become aware all too clearly in the global financial crisis, neither modern business systems nor advanced societies can ignore the importance of trust. It would be misleading to believe that trust can be replaced by contract enforcement or surveillance or confined to what Habermas (1984/1987) calls the 'lifeword'. Trust is a much more fundamental and an indispensable condition of creativity and innovation in all subsystems of 
This is the version of a forthcoming article accepted for publication in International Sociology published by Sage: http://iss.sagepub.com/content/by/year

Accepted version downloaded from SOAS Research Online: http://eprints.soas.ac.uk/22499/ and made available under the CC-BY-NC License

contemporary developed societies This is more than enough reason to place much more

emphasis on the study of trust than social scientists have done in times when trust was a

'given' rather than a scarce and challenged resource. This includes the analysis of different

forms of trust and their combinations with other social coordination mechanisms in country-

specific cultural and institutional settings as well as the consequences that emerge with regard

to various forms of cross-national exchange relationships. 
This is the version of a forthcoming article accepted for publication in International Sociology published by Sage: http://iss.sagepub.com/content/by/year

Accepted version downloaded from SOAS Research Online: http://eprints.soas.ac.uk/22499/ and

made available under the CC-BY-NC License

\section{References}

Adler PS (2001) Market, Hierarchy, and Trust: The Knowledge Economy and the Future of Capitalism. Organisation Science 12: 215-234.

Arnoldi J (2010) Sense Making As Communication. Soziale Systeme 16: 28-48.

Bachmann R (2001) Trust, Power and Control in Trans-Organisational Relations.

Organisation Studies 22: 337-365.

Bachmann R and van Witteloostuijn A (2009) Analyzing Inter-Organisational Relationships in the Context of their National Business Systems: A Conceptual Framework for Comparative Research. European Societies 11: 49-76.

Bachmann R and Inkpen A (2011) Understanding Institutional-based Trust Building

Processes in Inter-organisational Relationships. Organisation Studies 32: 281-301.

Beckert J (2006) Trust and Markets. In: Bachmann R and Zaheer A (eds) Handbook of Trust Research. Cheltenham: Elgar, pp. 318-331.

Berger PL and Luckmann T (1967) The Social Construction of Reality: A Treatise in the Sociology of Knowledge. Garden City, NY: Anchor.

Bijlsma-Frankema K and Costa AC (2005) Understanding the Trust-Control Nexus. International Sociology 20: 259-282.

Bradach J L and Eccles R G (1989) Price, authority, and trust: From ideal types to plural forms. Annual Review of Sociology 15: 97-118.

Chernilo D (2002) The Theorisation of Social Co-Ordinations in Differentiated Societies:

The Theory of Generalized Symbolic Media in Parsons, Luhmann and Habermas. British Journal of Sociology 53: 431-449. 
This is the version of a forthcoming article accepted for publication in International Sociology published by Sage: http://iss.sagepub.com/content/by/year

Accepted version downloaded from SOAS Research Online: http://eprints.soas.ac.uk/22499/ and made available under the CC-BY-NC License

Dinkel C (2001) Religious Faith as a Symbolic Generalized Medium of Communication.

Soziale Systeme 7: 56-70.

Dyer JH and Chu W (2003) The Determinants of Trust in Supplier-Automaker Relationships in the U.S., Japan, and Korea. Journal of International Business Studies 31: 259-285.

Ertug G, Cuypers I R, Noorderhaven N G and Bensaou B M (2013) Trust between international joint venture partners: Effects of home countries. Journal of International Business Studies 44: 263-282.

The Financial Times (2013) Chinese Chipmakers in 'Bloody' Price War. Available at: http://www.ft.com/cms/s/0/08456862-e93d-11e2-9f1100144feabdc0.html\#axzz3oko33CVZ

The Guardian (2011) British Farmers Forced to Pay the Cost of Supermarket Price Wars. Available at: http://www.theguardian.com/environment/2011/jul/02/british-farmerssupermarket-price-wars

Ganßmann H (1988) Money - a symbolically generalized medium of communication? On the concept of money in recent sociology. Economy and Society 17: 285-316.

Giddens A (1990) The Consequences of Modernity. Stanford, CA: Stanford University Press. Gillespie N Hurley R Dietz G and Bachmann R (2012) Restoring Institutional Trust after the Global Financial Crisis: A Systemic Approach. In: Kramer RM and Pittinsky TL (eds) Restoring Trust in Organisations and Leaders: Enduring Challenges and Emerging Answers. Oxford: Oxford University Press, pp. 185-211.

Grey C and Garsten C (2001) Trust, Control and Post-bureaucracy. Organisation Studies 22: 229-250.

Habermas J (1984/1987) The Theory of Communicative Action. 2 vols. Cambridge: Polity. Hall PA and Soskice DW (eds) (2001) Varieties of Capitalism: The Institutional Foundations of Comparative Advantage. Oxford: Oxford University Press. 
This is the version of a forthcoming article accepted for publication in International Sociology published by Sage: http://iss.sagepub.com/content/by/year

Accepted version downloaded from SOAS Research Online: http://eprints.soas.ac.uk/22499/ and made available under the CC-BY-NC License

Heckscher C and Adler P (eds) (2006) The Firm as a Collaborative Community:

Reconstructing Trust in the Knowledge Economy. Oxford: Oxford University Press.

Ingham G (2004) The Nature of Money. Cambridge: Polity.

Krause D (2005) Luhmann-Lexikon. Stuttgart: Lucius and Lucius.

Krieger DJ (1996) Einführung in die allgemeine Systemtheorie. Munich: Fink.

Kroeger F (2012) Trusting organizations: The institutionalization of trust in inter-

organizational relationships. Organisation 19: 743-763.

Kroeger F (2013) How is trust institutionalised? Understanding collective and long-term trust orientations. In: Bachmann R and Zaheer A (eds) Handbook of Advances in Trust Research. Cheltenham: Edward Elgar, pp. 261-284.

Lane C (1995) Industry and Society in Europe: Stability and Change in Britain, Germany and France. Aldershot: Elgar.

Lane C and Bachmann R (1996) The Social Constitution of Trust: Supplier Relations in Britain and Germany. Organisation Studies 17: 365-95.

Lane C and Bachmann R (1997) Co-operation in inter-firm relations in Britain and Germany:

The role of social institutions. British Journal of Sociology 48: 226-254.

Lewicki R J, Tomlinson E C and Gillespie N (2006) Models of interpersonal trust development: Theoretical approaches, empirical evidence, and future directions. Journal of Management 32: 991-1022.

Luhmann N (1976) Generalized Media and the Problem of Contingency. In: Loubser JL, Baum RC, Effrat A and Lidz VM (eds) Explorations in General Theory in Social Science: Essays in Honor of Talcott Parsons. New York: Free Press, pp. 507-532. Luhmann N (1979) Trust and Power. Chichester: Wiley.

Luhmann N (1981) Die Unwahrscheinlichkeit der Kommunikation. In: Soziologische Aufklärung, vol.3. Opladen: Westdeutscher Verlag, 25-34. 
This is the version of a forthcoming article accepted for publication in International Sociology published by Sage: http://iss.sagepub.com/content/by/year

Accepted version downloaded from SOAS Research Online: http://eprints.soas.ac.uk/22499/ and made available under the CC-BY-NC License

Luhmann N (1990) Der medizinische Code. In: Soziologische Aufklärung, vol. 5. Opladen:

Westdeutscher Verlag, 183-195.

Luhmann N (1995) Social Systems. Stanford, CA: Stanford University Press.

Luhmann N and Schorr KE (2000) Problems of Reflection in the System of Education.

Münster: Waxmann.

Luo Y (2002) Contract, cooperation, and performance in international joint ventures.

Strategic Management Journal 23: 903-919.

Marx K (1962) Marx-Engels-Werke (MEW), vol. 23: Das Kapital, vol. I. East Berlin: Dietz.

Möllering G (2005) The Trust/Control Duality: An Integrative Perspective on Positive

Expectations of Others. International Sociology 20: 283-305.

Morgner C (2014) The theory of love and the theory of society: Remarks on the oeuvre of

Niklas Luhmann. International Sociology 29: 396-404.

Murphy JW (1987) Niklas Luhmann: His Contribution to the Sociology of Religion.

International Sociology 2: 205-213.

Nooteboom B (2006) Forms, Sources and Processes of Trust. In: Bachmann R and Zaheer A (eds) Handbook of Trust Research. Cheltenham: Elgar, pp. 247-263.

Parsons T (1967) On the Concept of Political Power. In: Sociological Theory and Modern Society. New York: Free Press, pp. 352-404.

Parsons T (1977) Social Structure and the Symbolic Media of Interchange. In: Social Systems and the Evolution of Action Theory. New York: Free Press, pp. 204-228.

Powell WW (1990) Neither market nor hierarchy: Network forms of organisation. Research in Organisational Behavior 12: 295-336.

Powell WW (1996) Trust-Based Forms of Governance. In: Kramer RM and Tyler TR (eds) Trust in Organisations: Frontiers of Theory and Research. London: Sage, pp. 51-67. 
This is the version of a forthcoming article accepted for publication in International Sociology published by Sage: http://iss.sagepub.com/content/by/year

Accepted version downloaded from SOAS Research Online: http://eprints.soas.ac.uk/22499/ and made available under the CC-BY-NC License

Rotter JB (1967) A new scale for the measurement of interpersonal trust. Journal of

Personality 35: 651-665.

Rousseau DM, Sitkin SB, Burt RS and Camerer C (1998) Not so different after all: A crossdisciplinary view of trust. Academy of Management Review 23: 393-404.

Rus A and Iglic H (2005) Trust, Governance and Performance: The Role of Institutional and Interpersonal Trust in SME Development. International Sociology 20: 371-391.

Sako M (1998) Does Trust Improve Business Performance? In: Lane C and Bachmann R (eds) Trust Within and Between Organisations: Conceptual Issues and Empirical Applications. Oxford: Oxford University Press, pp. 88-117.

Simmel G (1950) The Sociology of Georg Simmel. (Ed. KH Wolff.) New York: Free Press. Simmel G (1990) The Philosophy of Money. London: Routledge.

Schreyögg G and Sydow J (2011) Organisational Path Dependence: A Process View. Organisation Studies 32: 321-335.

Sydow J (2006) How can systems trust systems? A structuration perspective on trust-building in inter-organisational relations. In: Bachmann R and Zaheer A (eds) Handbook of Trust Research. Cheltenham: Elgar, pp. 377-396.

Sztompka P (1996) Trust and Emerging Democracy: Lessons from Poland. International Sociology 11: 37-62.

Tillmar M and Lindkvist L (2007) Cooperation Against All Odds: Finding Reasons for Trust where Formal Institutions Fail. International Sociology 22: 343-366.

Whitley R (1992) European Business Systems: Firms and Markets in their National Contexts. London: Sage.

Williamson OE (1985) The Economic Institutions of Capitalism. New York: Free Press. Williamson OE (1993) Calculativeness, Trust, and Economic Organisation. Journal of Law and Economics 36: 453-486. 
This is the version of a forthcoming article accepted for publication in International Sociology published by Sage: http://iss.sagepub.com/content/by/year

Accepted version downloaded from SOAS Research Online: http://eprints.soas.ac.uk/22499/ and made available under the CC-BY-NC License

Zaheer A, McEvily B and Perrone V (1998) Does Trust Matter? Exploring the Effects of

Interorganisational and Interpersonal Trust on Performance. Organisation Science 9:

141-159.

Zaheer A, Gulati R and Nohria N (2000) Strategic Networks. Strategic Management Journal 21: 203-215.

Zucker LG (1986) Production of Trust: Institutional Sources of Economic Structure, 18401920. Research in Organisational Behavior 8: 53-111. 
This is the version of a forthcoming article accepted for publication in International Sociology published by Sage: http://iss.sagepub.com/content/by/year

Accepted version downloaded from SOAS Research Online: http://eprints.soas.ac.uk/22499/ and made available under the CC-BY-NC License

\section{Table 1}

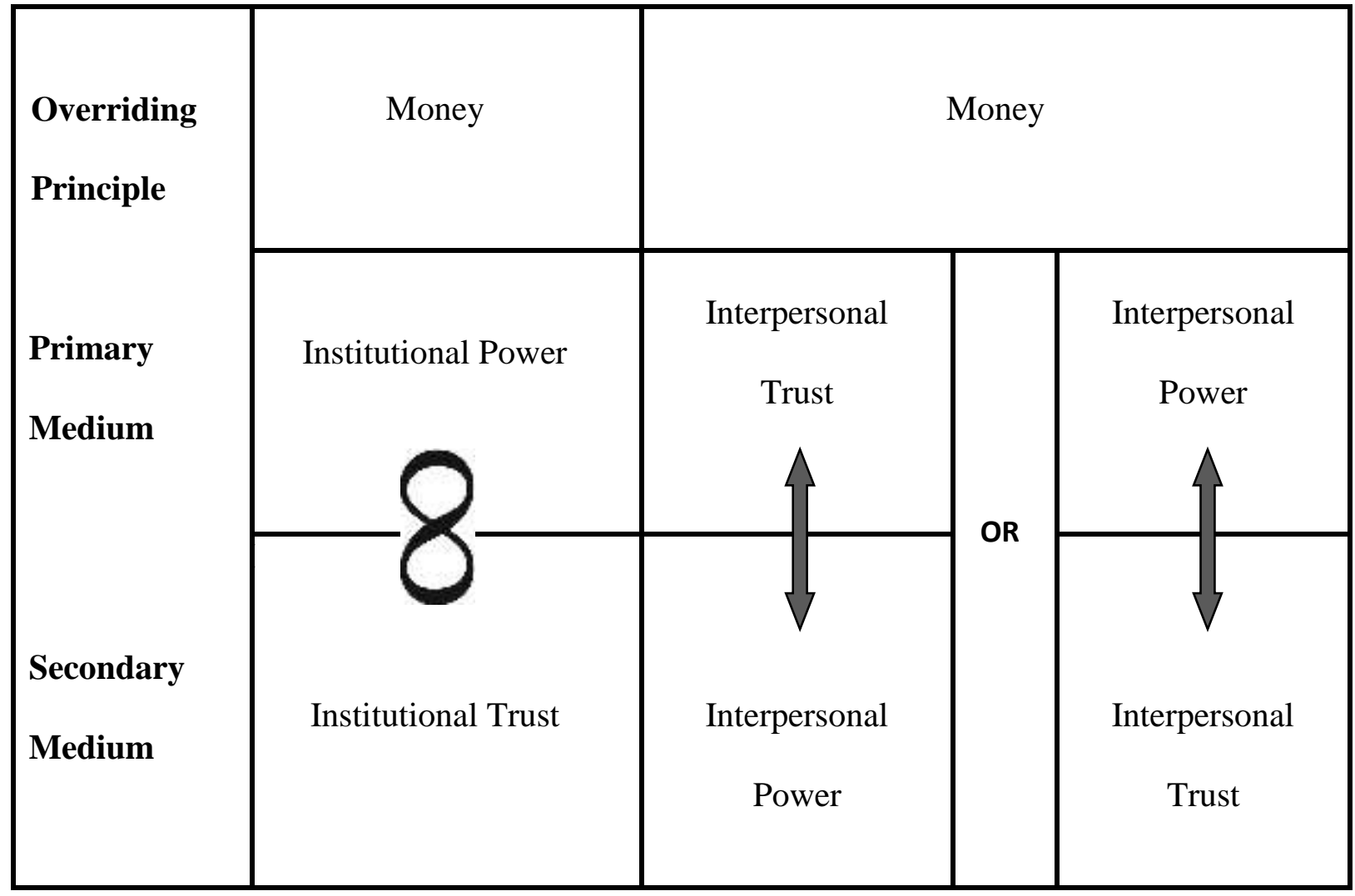


This is the version of a forthcoming article accepted for publication in International Sociology published by Sage: http://iss.sagepub.com/content/by/year

Accepted version downloaded from SOAS Research Online: http://eprints.soas.ac.uk/22499/ and made available under the CC-BY-NC License

Table 2

\begin{tabular}{|c|c|c|c|c|}
\hline $\begin{array}{l}\text { Primary } \\
\text { Medium }\end{array}$ & $\begin{array}{c}\text { Collectively Controlled } \\
\text { or Small Money }\end{array}$ & $\begin{array}{c}\text { Individually } \\
\text { Available or Large }\end{array}$ & & $\begin{array}{c}\text { Interpersonal } \\
\text { Trust }\end{array}$ \\
\hline $\begin{array}{l}\text { Secondary } \\
\text { Medium }\end{array}$ & Institutional Trust & $\begin{array}{c}\text { Interpersonal } \\
\text { Trust }\end{array}$ & & $\begin{array}{l}\text { Individually } \\
\text { Available or } \\
\text { Large Money }\end{array}$ \\
\hline $\begin{array}{l}\text { Underpinning } \\
\text { Principle }\end{array}$ & Power & & Power & \\
\hline
\end{tabular}


This is the version of a forthcoming article accepted for publication in International Sociology published by Sage: http://iss.sagepub.com/content/by/year

Accepted version downloaded from SOAS Research Online: http://eprints.soas.ac.uk/22499/ and made available under the CC-BY-NC License

Table 3

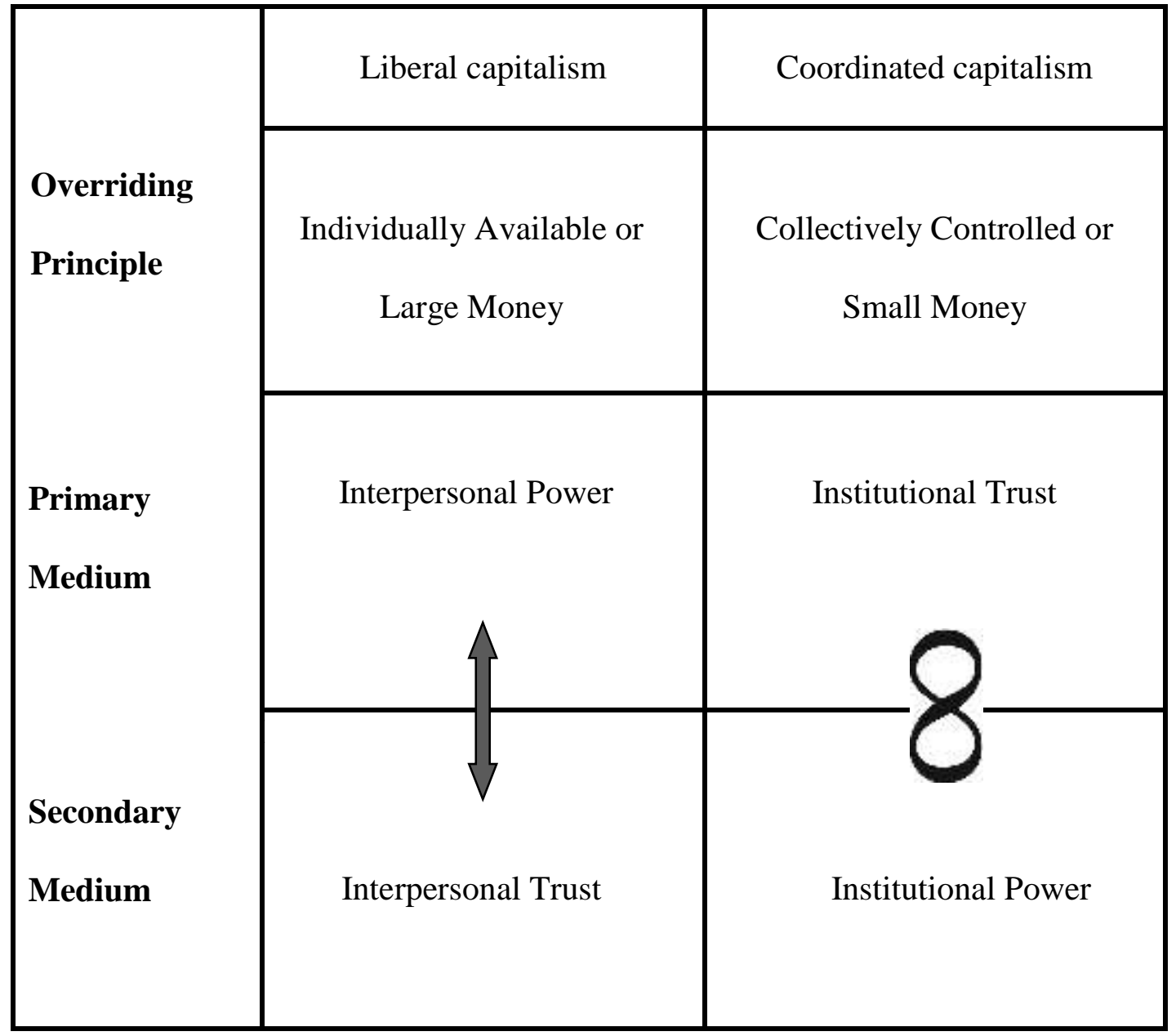

